\title{
Limitación del Poder por el Derecho
}

\author{
Raitl Ferrero.
}

El Poder. se halla ligado por el Derecho. Esta limitación del Poder, tan necesaria en la época autoritaria por la que atraviesa el munco. ticne tres aspectos:

a) Limitación del Poder por la Constitución.

b) Responsabilidad del Estado Legislador.

c) Resistencia a la opresión.

\section{A).-LIMITACION DEL PODER POR LA CONSTITUCION}

El ejercicio del Poder dentro de la comunidad estatal está orgaganizado por un conjunto de disposiciones fundamentales que forman el estatuto constitucional, llamado corrientemente la Constitución. Tales disposiciones instituyen los órganos o poderes del Estado, establecen sus relaciones precisas y definen el grado de autoridad reconocido a cada uno de ellos, trazando la esfera de su competencia. Además, y esto de modo fundamental, pueden restringir la totalidad del Poder, sometiéndolo a numerosas limitaciones de Derecho, a fin de asegurar la libertad de la persona frente a la omnipotencia del Estado, armado por tan formidable poder de compulsión. En virtud del mismo estatuto, sus disposiciones pueden ser sustraídas de la competencia del legislador ordinario de tal manera que sólo una reforma constitucional pueda invalidarlas o modificarlas. El Poder público, y particularmente el Poder Ejecutivo, debe conformar sus relaciones con los administrados a las reglas jurídicas preestablecidas. Pero esta limitación no es posible sino en el caso de que un juez reprima los abusos, condenando el atentado que se haga contra la Constitución.

En primer lugar, los jueces, antes de aplicar una ley deben asegurarse de que ella ha sido dictada por las Cámaras y promulgada 
por el Ejecutivo. Por lo menos, han de asegurarse de que la ley ha sicio debidamente promulgada. Cree Duguit que no compete a los jueces constatar que la ley promulgada sea igual al proyecto aprobado por las Cámaras. Deben verificar sólamente si la ley ha sido votada por las Cámaras, pues de otra manera sería un simple reglamento, invalidable por los jueces si éstos lo estiman contrario a la ley. El texto de la ley es, para los jueces, aquel que es promulgado por el Jefe del Estado, aún cuando haya sucedido a veces, como con la ley francesa del 5 de agosto de 1914, cue el texto oficial difiera del aprobado por las Cámaras. Fischbech considera que la pronulgación sienta para todos, particulares y autoridades, la presunción irrefragable de que la ley, tal como aparece transcrita en el órgano oficial, refleja fielmente la voluntad del legislador, y es, por tanto, auténtica.

Los nuevos derechos sociales y económicos han determinado el aumente de los derechos declarados inviolables por las Constituciones. Las constituciones americanas y las europeas de la post-guerra contienen declaraciones de derechos. Con todo, es curioso anotar, siguiendo a Lambert, Profesor de la Facultad de Derecho de Lyon, que las Constituciones que limitan más detalladamente el Poder han resultado las menos observadas, como en Méjico, o de corta duración, como la alemana de Weimar. Y es que tal proclamación de los derechos fundamentales no tiene más valor que el que efectivamente le concecan la cultura cívica de un pueblo y el respeto de sus gobernantes por las leyes. Así, en Inglaterra el Parlamento podría modificar la constitución en cualquier momento, pues no existiendo una constitución rígida, bástales a las Cámaras dar una ley para abrogar la anterior, aún cuando tenga siglos de tradición. En Inglaterra es igual el procedimiento parlamentario para una ley sobre libertades públicas' como para otra sobre fabricación de conservas. Y sin embargo, jamás se ha pensado en crear un tribunal encargado de apreciar la conformidad de las leyes al derecho, a pesar de que no se distingue entre leyes constitucionales y leyes ordinarias. La fuerza de la opinión y la majestad del Poder Judicial son la mejor garantía contra la arbitrariecad del legislador.

El control judicial de la constitucionalidad de las leyes existe, marcadamente, en los Estados Unidos de Norte América. Por más que se haya discutido ardientemente entre los detractores y los defensores del sistema si éste se basaba en la propia Constitución, es evidente que la carta fundamental lo contiene implícitamente. En la sección 2 de su artículo VI establece que: "La Constitución y las leyes re los Estados Unidos..... serán la ley suprena del país; y en todos los Estados los jueces estarán ligados por ellas. no obstante todo lo pudieran establecer en contrario las constituciones y las leyes de los 
Estados". Tal control era históricamente indispensable para pasar del frágil federalismo de los años iniciales a la vigorosa nacionalidad del presente. Pero, en cuanto a la defensa de las libertades individuales contra la absorción del Estado, la constitución es mucho menos clara. Recién en el año 1803 se introdujo en el derecho constitucional americano este método de defensa contra los abusos del Poder Público.

E.1 Presidente de la Corte Suprema Federal, John Marshall, estableció la doctrina en el caso célebre de Barbury contra Madison. Sin invocar los precedentes históricos ni las opiniones de los autores de ia Constitución de Filadelfia, Marshall presentó dicha doctrina comó una lógica derivación del rol que los jueces deben cumplir en la apliración primordial de las leyes. Según Marshall, cuya excelente fundamentación ha sido repetida varias veces en Europa, "La atribución del poder judicial es esencialmente la de decir lo que es la ley. Los que aplican la regla a los casos particulares deben necesariamente exponer e interpretar esta regla. Si dos leyes están en conflicto. la corte debe determinar el campo de aplicación de cada una. Si una ley está en uposición con la Constitución.... la corte debe determinar cuál de las r eglas en conflicto rige el caso. Es la esencia misma del poder judicial. Un acto de la legislatura contrario a la Constitución, es nulo. No podría obligar a las cortes. Los jueces deben aplicar la ley superior y descartar la ley inferior que le es contraria".

La doctrina sentada por Marshall fué actualizada y vigorizada mucho más tarde, después de la guerra de secesión. Después del largó conflicto, se agregó una declaración de derechos a la Constitución Federal (sección I de la enmienda XIV), por la que se ratificaban $y^{r}$ ampliaban las limitaciones impuestas al legislador por la Constitución. Se hacía extensiva tal limitación a los legisladores de los Estados miembros de la Unión. La doctrina de la inconstitucionalidad de las leyes fué estableciéndose sobre las dos cláusulas de esta declaración (igual protección de las leyes e interdicción a todo Estado de privar a una persona de su vida, su libertad o su propiedad, sin "procedimiento regular de derecho") y de la eláusula de la sección 10, parrágrafo $\mathrm{I}$, artículo $1^{\circ}$ de la Constitución. por la que se prohibe al legislador federal debilitar el efecto de las obligaciones.

La cultura política del país hizo que no se aplicara la declaración de la enmienda XIV sino para su objeto inicial, o sea, la protección de los negros. Pero más tarde, se hán venido acogiendo a ella los capitanes de industria para defenderse contra la intervención del Estado y la creciente fiscalización de sus negocios. Desde los primeros años de este siglo, la Corte Federal ha venido dando mayor amplitud al control judicial de la constitucionalidad de las leves. Así. el año 1905, en el famoso caso Lochner, la Corte resolvió, por cinco votos contra cua- 
tro, declarar nula una ley del Estado de New York que limitaba a diez horas la jornada de trabajo en las panaderías. Consideraba la Corte que dicha ley privaba a los empleados de su libertad y de su propiedad sin "procedimiento regular de derecho" (due process of law).

Del año 1890 hasta la época actual, la Corte ha debido resolver sobre multitud de reclamaciones presentadas por aquellos a quienes cifectaban en sus intereses las nuevas leyes sociales y de protección cconómica. Tal sucedió con las leyes sobre accidentes de trabajo, de duración de la jornada, de remuneración del trabajo o de sus condiciones, las leyes contra las oficinas privadas de colocación y contra la prohibición de pertenecer à sindicatos obreros que los patronos incluían en los contratos de trabajo. Ioualnente. fueron sometidas a las Cortes, las leyes que establecian el arbitraje obligatorio para los confictos del trabajo, el salario minimo, o la legitimación de los instrumentos de presión sindical contra los patronos, como el boicot y e. picketing. Las nuevas leyes de impuestos y tasas al comercio y a la industria han sido apeladas ante le Suprema Corte, la que declaró inconstitucional. recientemente, una de las leyes fundamentales para el New Deal del Presidente Rooserelt.

Los recursos ante el poder judicial tienen por objeto que éste constate la inconstitucionalidad de las medidas decretadas y proceda a cieclarar, en consecuencia, su inaplicabilidad. Los recursos se fundamentan casi siempre en las cláusulas de las enmiendas $\mathrm{V}$ y XIV, que prohiben privar a nadie de sus derechos sin "duc process of law". Ahora bien, ¿qué es lo que se debe entender por "due process of law", o sea, por "procedimicnto regular de derecho"? La Corte Suprema, dice el juez Day, ha tenido frecuentes ocasiones de analizarlo y siempre ha rehusado dar una significación precisa, prefiriendo dejar el campo de aplicación a la decisión judicial a medida que surjan los procesos. Si bien los jueces se han querido reservar, pues, un derecho ilimitado para controlar en interés público las intervenciones del Poder, también se han trazado algunas directivas según . las cuales ejercen su derecho de control constitucional. Los jueces siguen tres criterios para determinar si las leyes incriminadas son constitucionales o no.

El primer criterio seguido es el de que la ley constituya un ejercicio razonable y proporcionado de las facultades de policía del Estado. Si representa una intervención disproporcionada o no razonable, la ley se declara inconstitucional. El segundo criterio es el de que los medios empleados por la ley para conseguir sus fines sean necesarios jara ello; de lo contrario, es decir, si tales fines de interés público pueden ser alcanzados con una menor restricción de los derechos individuales, la ley es declarada insubsistente. Tal criterio (expediency) 
ha sido muy empleado para la apreciación de las leyes de carácter social y económico con que cada día viene invadiendo la esfera privada el Estado. El tercer criterio es el de que las leyes sociales y económicas que establecen sanciones penales para los infractores especifiquen bien claramente aquello que se permite y aquello que se prohibe. Con mucha frecuencia, los tribunales han declarado la invalidez. de una ley por adolecer de esta falta de certeza y claridad.

Los tribunales ejercen su control legislativo por cuatro procedimientos establecidos por la práctica. El primer procedimiento es el de excepción de inconstitucionalidad. El querellante, procesado por incumplimiento de una ley, o demandado para que la cumpla, ejerce como medio de defensa la inconstitucionalidad de la ley, sometiéndola así a la consideración de la corte. Con frecuencia, el querellante es in agente de los grupos afectados por la ley y que se valen de este medio para obligar a la corte a calificar la constitucionalidad de la ley. Cuando la más alta corte del Estado, mejor aún si es la propia Corte Suprema Federal, declara que la ley es inaplicable por inconsitucional, ésta queda prácticamente anulada por efecto de la doctrina del stare decisis, que obliga a los jueces inferiores a seguir la regla establecida por la jurisprudencia suprema, cuyas decisiones son llamadas ejecutorias porque establecen precedente forzoso. La legislatura no tiene ya más recurso que aprobar una nueva ley que no contenga ninguna de las disposiciones censuradas por los tribunales, o bien, votar una reforma constitucional, llamada enmienda, que le confiara expresamente el derecho a realizar la reforma que deseaba. Numerosas veces han recurrido a este medio las legislaturas de los Esstados. La legislatura federal se ha visto obligada también a emplear tal recurso después de las declaraciones de inconstitucionalidad efectuadas por la Corte Suprema en 1918 y 1922 sobre las leyes regulando el trabajo de los menores. Así debió votar, el 2 de junio de 1924 una enmienda constitucional que confería al Congreso "el poder de limitar, reglar y prohibir el trabajo de las personas menores de 18 años". Pero la enmienda, que necesitaba la aprobación de 36 Estados para regir, no pudo obtener sino la adhesión de 20 Estados.

El segundo procedimiento es el de la demanda de injonction (mandamiento $u$ orden). Los interesados se adelàntan a la aplicación de la ley, aún antes de haber sido perturbados en el goce de su situación jurídica. Piden a los tribunales que prohiban al Poder Ejecutivo, mediante una orden o mandamiento, poner en aplicación la ley inconstitucional. Por este procedimiento se consiguió impedir la aplicación de la ley, aprobada después de la guerra mundial, por la que se prohibía la enseñanza del alemán en las escuelas. El tercer procedimiento consiste en que la corte se avoca de oficio el examen de la 
constitucionaliclad de una ley. Tal sucedió, por ejemplo, con su cébre decreto de 1803, que constituye el acta de nacimiento del control indicial. El cuarto procedimiento, sumamente complejo, es el del aziso consultio, cue ha trascendido del derecho constitucional americano a la praictica de la Corte Permanente de Justicia Internacional.

Precisamos, en sintesis de lo expuesto, que el sistema consiste (n) oponer a la ley la excepción de inconstitucionalidad, dando así ocasión para que los tribunales aprecien y califiquen la ley. Si los tribunales la juzgan inconstitucional, se niegan a aplicarla. Pero no la anulan ni derogan, pues no tienen competencia para ello; simplemente, la dejan sin eficacia, ya que, por el principio del stare decisis, los jueces inferiores deben aplicar la jurisprudencia establecida por el tribunal superior.

En Francia ha sido tradicional negar al poder judicial competencia para declarar sobre la constitucionalidad de una ley. Así resulta del art. $3^{\circ}$ del capítulo $V$ del título IIT de la Constitución de 1791, según el cual "los tribunales no pueden mezclarse en el ejercicio del poder legislativo, ni suspender la ejecución de las leves". También el art. 10 del título II de la ley de 16 de agosto de 1790 prescribía: "Los tribunales no podrán... impedir o suspender la ejecución ve los decretos del cuerpo legislativo..." En virtud de la separación de poderes, $y$, consecuentemente, de la competencia exclusira cle cada : ino, se ha negado en Francia el derecho de los jueces para calificar la constitucionalidad de una ley, en un caso a ellos sometido por las partes. Tal es la tesis sostenida por Esmein. Pero Duguit opina, rectificánclose de sus anteriores afirmaciones, que semejante doctrina es errónea. "El principio de la separación del poder legislativo y la autoridad judicial no puede compeler a un tribunal a aplicar una ley inconstitucional. Los tribunales están obligados a aplicar las leyes, es incontestable; pero deben aplicar tanto las leyes constitucionales como las leyes ordinarias. Por lo tanto, si hay contradicción entre la ley ordinaria y la ley constitucional, es ésta la que debe prevalecer, puesto que es la ley superior, y es ella, solamente ella, la que deben aplicar los tribunales. Decir que los tribunales no tienen competencia para apreciar la constitucionalidad de una ley y que están obligados a aplicar todas las leyes, incluso una ley contraria a la Constitución, equivale a decir que pueden violar la Constitución, lo que no es admisible".

Respecto de la aplicación de los reglamentos, si es opinión unál. nime en Francia que los tribunales tienen competencia para apreciar la legaliclad de los reglamentos, inclusive los gure enmanen del Jefe del Estado y los reglamentos formulados por el Eijecutivo a peticion o por encargo de las Címaras. En nuestro país, el art. 154 de la Cons- 
titución establece que el Jefe del Estado tiene entre sus atribuciones la de reglamentar las leyes, sin trasgredirlas ni desrirtuarlas, y que la misma restricción existe para los decretos y resoluciones. El art. 133 de la misma carta establece: "Hay acción popular ante el poder judicial contra los reglamentos y contra las resoluciones y decretos gubernativos de carácter general que infrinjan la Constitución o las Leyes, sin perjuicio de la responsabiliclad política cle los Ministros". El Código Civil establece, en el art. XXI del Título Preliminar que "los Jueces no pueden dejar de aplicar las leyes".

Resultados dol sistema.-En los Estados Unidos de Norte Amé$z$ ica, el control judicial de la constitucionalidad de las leyes, ha derivado en una verdadera suprenacía de los jueces sobre la legislatura. O sea, que los tribunales se hallan, prácticamente, en condición de invalidar los acuerdos que toman los representantes del pueblo, quienes, en teoría, detentan la soberanía nacional por delegación popular. Ch. Grove Haines ha desarrollado brillantemente este tema en su obra "American doctrine of judicial supremacy". Se critica al sistenna el ser el gobierno de las leyes y no el de los hombres. Bajo pretexto de control sobre la constitucionalidad de las leyes, el Poder Judicial ha ido adquiriendo dos instrumentos de dirección política y social. Mediante la apreciación de las leyes, los tribunales corrigen o eliminan las disposiciones que estiman inconstitucionales. Y, mediante el injonction o mandamiento, los tribunales intervienen en los contictos del trabajo para prohibir a las organizaciones obreras el empleo de determinados instrumentos de lucha, como el boycott o la llamada "conscripción de neutros". Desde el año 1934, la Corte Fedesal, gracias al criterio de los nuevos jueces, ha venido mostrando una mejor comprensión para las leyes de carácter económico-social. Así, en la célebre resolución del 18 de febrero de 1935 reconoció comó válida la ley que antula, por ser contrarias al orden público, las cláusulas contractuales en las que se estipule el pago en oro. Este cambio de orientación de la Corte Federal ha contribuído notablemente a que la opinión pública ratifique su adhesión al sistema del control judic:al.

Sistema de Tribunal Constiturional Especial-Para asegurar mejor el control sobre la constiturionalidad de las leyes, se ha querido establecer Tribunales especiales, como el Senado conservador en Francia durante el Consulado, el Primer Imperio y el Segundo Imperio. La constitución de Rumania ha reservado el examen de la consłtucionalidad de las leyes a la Corte de Casación en pleno. La consritución de Checoesloraquia prohibía a los jueces, por su art. 102, discutir la constitucionalidad de las leyes regularnente promulgadas. 
Lero, por ley posterior y conforme al espíritu del mismo artículo, se estableció un Tribunal Constitucional, cuya composición, derivada del Poder, no ofrecía garantias de imparcialidad. La unica experiencia de verdadera importancia ha sido la de Austria. La constitución austriaca de 1920 estableció ma Alta Corte Constitucional, institución que fué mantenicla por las Constituciones de 1928 y 1937. Esa Alta Corte protegía los derechos individuales y mantenía a lus jueces alejados de la política. Como imitación de la institución austriaca, la últina constitución española estableció el Tribunal de Garantías constitucionales, entre cuyas atribuciones se contaba la de apreciar la constitucionalidad de las leyes. La institución se debió a la inspiración del jurista Hans Kelsen, a quien Karl Schmitt opone la tesis de que un organismo jurídico no es un órgano eficiente de garantía constitucional. Pero ninguno de estos ensayos puede ser comparado con la construcción, realmente admirable, a que han llegado los Estados Lnidos después de más de un siglo de tradición y reajustes.

Compendiando la crítica del sistema podemos repetir la observación de Duguit: "El sistema, que consiste en conferir a una alta e imparcial jurisdicción, sin carácter político, competencia para apreciar las leyes, desde el punto de rista del derecho, y para anular las leyes que contengan preceptos atentatorios al derecho, parece a primera rista tan seductor como de fácil realización. $\mathrm{Y}$, sin embargo. cuando se reflexiona un poco, surge la duda y se pregunta uno si verdaderamente sería ésta la solución ideal y habríamos dado con una institución colocada por encima de toda controversia y suspicacia. Por de pronto, ¿ cómo estaría compuesta esta alta jurisdicción. y cómo habrían de ser designados sus miembros? Si es el Gobierno o el Parlamento quien los nombra, su independencia estaria en litigio. Si son elegidos por el pueblo, por sufragio directo o de dos grados, esta a'ta jurisdicción vendría a ser un organismo político y no presentaría las garantías de imparcialidad que se le piden. Si se reclutan por cooptación, la institución asi constituída no tardaria en converiirse en una corporación aristocrática y sus miembros erigidos en casta, incompatible con la democracia moderna".

Aún suponiendo que dicha corte sea posible, quedaria siempre por resolver cuál ha de ser la forma de su intervención. Porque si correspondiera sólo al Gobierno el ejercicio de la instancia, es evidente que no la ejercitará sino en el caso de que desee invalidar una ley que no le complace. Si cualquier persona pudiera ocurrir ante dicho tribunal solicitando se declare inaplicable una ley, entonces tendriamos un entorpecimiento a la labor legislativa, que se supone de bien público, por la sola acción de un individuo afectado. Por último. 
si ese tribunal pudiera intervenir de oficio e invalidar una ley por jropia iniciativa, entonces se tendría un nuevo órgano político más poderoso que el Estado mismo.

\section{B) RESPONSABILIDAD DEL, ESTADO LEGISLADOR}

Aunque las leyes más recientes tienden a desconocerlos, por la creciente impulsión de la solidaridad social, existen dos principios ju:ídicos que toda ley debe respetar, por lo menos de modo general; ellos son el de los "derechos adquiridos" y el de la "irretroactividad de las leyes". El legislador que los vulnere, sin que un urgente interés público lo exija, desprestigia la autoridad del Esstado y mina la base de la armonía social, cual es la confianza en la seguridad de las situaciones jurídicas. Cuando una ley no está arreglada a derecho, el particular tiene recursos para evitar la aplicación de la ley; tales recursos son la apelación judicial y la resistencia. Pero, en el caso de que ma ley sea perfectamente legitima, esto es, conforme a derecho, bien puede suceder que cause perjuicios a determinadas personas. Hasta liace muy pocos años se estimaba generalmente que el Estado no era responsable por los perjuicios que ocasionara una ley. Se creía que el Farlamento era el intérprete infalible de la soberanía nacional y que no podia existir ningún derecho superior o distinto al que él definiera.

Felizmente, hoy va abriéndose campo la conciencia de que la ley no crea el derecho por sí misma y que su valor jurídico está en relación con un derecho anterior $y$ superior a ella. El patrimonio del Estado se halla en la obligación cle reparar los perjuicios que una ley ocasione al patrimonio de los particulares, salvo casos excepcionales de interés público. El conocicho tratadista Duguit ha establecido cuatro categorias, en las que se agrupan los casos cuestionables.

1.-El legislador dicta una ley para impedir o restringir cierta actividad, libre hasta entonces, pero que, en un momento daclo, se considera pcligrosa para el desenvolvimiento de la actividad individual y, por lo tanto, de la nación.-Si el legislador se ha propuesto stuprimir una actividad nociva para las personas y para la nación, el jatrimonio colectivo no tiene por qué indemnizar al patrimonio de algunos. Nada dice el hecho de que esa misma actividad ha sido considerada lícita anteriormente y que a su amparo se han creado intereses que la nueva ley lesiona. El derecho no es un conjunto de reglas absolutas e inmutables, sino un cuerpo de reglas variables con el tiempo y las circunstancias, según las nuevas necesidades del bien común, 
que es el que interesa a la socieclad. Cuando se dicta una ley prohibiendo una actividad anti-social, como la fabricación de productos nocivos, no puede pedirse una indemnización alegando que dicha actividad era anteriormente lícita puesto que, en realidad, se trataba de una omisión de la ley anterior y la nueva ley no hace sino reconocer y proclamar una prohibición que ya existía en puro derecho.

$2^{\circ}$ - El leyislador dicta una ley que prolibe o restringe determinada actizidad que no es, on si misma, nociza ni anti-social.Tal es el caso cuando el Estado asume para sí el ejercicio de una actividad privada con el fin de cumplirla más eficientemente o para establecer un monopolio. Es evidente que entonces el Estado se halla en la obligación de indemnizar a los particulares puesto que éstos se ven perjudicados en el ejercicio de una actividad conforme al derecho y que en nada perjudica a los demás. Si el Estado desea susti-! tuirse a los particulares, para obtener un lucro, es justo que indemnice por el perjuicio que ocasiona. Si el Estado asume una actividad porque estima que constituye un servicio público que él puede cumplir con mayor eficiencia, también debe pagar una indemnización iesde que priva a los particulares de una fuente de riqueza perfectamente lícita y plenamente jurídica. Es justo que el patrimonio colectivo, enriquecido por esta expropiación, compense el perjuicio que ocasiona.

$3^{\circ}$ - El legislador dicta una loy por la que restringe el derecho de los acrecdores.-Cuando una ley modifica situaciones contractuales nacidas con anterioridad a su promulgación, el Estado se halla en la obligación jurídica de indemnizar los perjuicios que ocasiona. Pero, para que sea debida la indemnización, precísase que la ley tenga por objeto modificar la situación jurídica en sí misma. No es exigible la indemnización si la ley se limita a modificar tan solo los términos de tiempo o las rías de ejecución, que farorecen a los acreedores. Así, las leyes que establecen moratorias o suspenden los efectons de la prescripción $y$ la carlucidad, obedecen a un interés social $y$ no afectan el derecho sustantivo de los acreedores: trútase ínicamente de reglas procesales y adjetivas. En cambio, si una ley modificara la situación jurídica misma, como sería el caso en que condonara los alquileres derengados o los intereses de los créditos, entonces si que el Estado estaría obligado a indemnizar por el perjuicio que ocasiona.

$4^{\circ}$ - El legislador dicta ma ley que, considerada en si misma, es conforme al derecho superior, pero que tiene por consecuencia hacer más onerosa la situación jurídica cn que se encontraba ma per- 
sona respecto al Estado.-Desde luego, no se trata aquí del caso improbable en que el Estado pretendiera modificar a su favor las condiciones contractuales que pactó con algún particular, puesto que tal jey sería simplemente una ley formal, de valor jurídico nulo y, por tanto, inaplicable en los tribunales. Cuando la ley es general, el Estado no debe indemnización a las personas afectadas por ella. Así, una ley que establece la liberación condicional, lo que supone menor número de presos, no obliga al Estado a indemnizar a los proveedores que contrataron con él un servicio de mayor magnitud. Igualmente, una ley de accidentes del trabajo, no obliga al Estado a indemnizar a los contratistas de las obras públicas por el mayor gasto que se les impone. Pero, si la ley tiene por objetivo especial el de modificar la situación jurídica de un concesionario de servicios públicos, haciéndola más onerosa, el Estado se halla obligado por el derecho superior a pagar la correspondiente indemnización, salvo cuando se trate de prescripciones reglamentarias dictadas para asegurar un mejor servicio.

\section{C) RESISTENCIA A LA OPRESION}

Toda persona tiene el derecho de exigir que el Estado se organice en tal forma que los derechos individuales sean respetados. Y el Esstado no respetará a los ciudadanos sino en aquellos países en los cue se haya establecido, enérgicamente, la responsabilidad de los funcionarios y la del propio Estado. Cuando, pese a todas las garantias constitucionales, los derechos individuales son violados, se dice que sxiste opresión, o sea, cuando el Estado dicta una ley contra el derecho, cualquiera que sea la mayoría que respalde dicha opresión. También es opresivo un acto individual para todos los miembros de la sociedad, porque, aún cuando no los afecte directamente, se está vulnerando el principio de la solidaridad social y haciendo sufrir a una persona una opresión que luego se puede continuar ejerciendo sobre las demás.

El art. 32 de la Declaración de Derechos de los girondinos decía: "Hay opresión cuando una ley viola los derechos naturales, civiles y políticos que debe garantizar. Hay opresión cuando se viola la ley por los funcionarios públicos al aplicarla a hechos individuales. Hay opresión cuando los actos arbitrarios violan los derechos de los ciudadanos contra la expresión de la ley. En todo gobierno libre, el modo de resistencia a estos diferentes actos de opresión debe ser regulado por la constitución". Los artículos 10 y 11 de la Declaración de Derechos de la Constitución de 1793 establecían: "Todo ciuda- 
dano llamado o requerido por la autoridad de la ley, debe obedecer al instante; la resistencia le hace culpable. Todo acto ejercido contra tin hombre fuera de los casos y sin las formas que la ley determina, es arbitrario y tiránico; aquel contra el cual se quisiera ejecutarlo por la violencia tiene el derecho de rechazarlo por la fuerza".

El art. 35 de la misma Declaración decía: "Cuando el Gobierno riola los derechos del pueblo, la insurección es para el pueblo y para cada porción del pueblo el más sagrado de los derechos y el más indispensable de los deberes". Los legisladores de entonces fueron todavía más lejos, hasta el extremo de justificar el tiranicidio: "Que toco individuo que usurpase la soberanía sea muerto al instante por los hombres libres" (art. 27). Este último artículo resulta monstruoso. Como afirma Duguit, el asesinato político es siempre un asesinato. Nada puede justificar que se prive de la vida a un hombre cualquiera, sin previo proceso judicial, rodeado de las máximas garantias de imparcialidad y defensa. Y si la ríctima es un Jefe de Estado, el delito reviste una gravedad moral indiscutible. En primer lugar, un individuo cualquiera, frecuentemente un anormal, se toma el derecho de juzgar y condenar ante sí a un Jefe de Estado y ejecuta su ase-. sinato. Fn segundo lugar, el clar muerte a un Jefe de Estado, el atentar contra su vicla, produce graves alteraciones politicas que causan a un país perjuicios a menudo irreparables. Inclusive el asesinato origina males mucho más efectivos y mayores que aruellos a los que pretendió poner fin el honicicla. Por lo clenás, es verdaderamente monstruoso que se reconozca a carla cual el derecho de juzgar al soberano en stu propia conciencia y de conclenarlo a muerte, con olvido $\because$ prescindencia de los daños que se va a ocasionar.

Locke (1632-1704) sostiene que la mayoría del pueblo puede ejercer el derecho de resistencia contra una autoridad tirinica. E1 poeta Nilon (1608-167t) justificó el regicirlio de Carlos I, exponiendo sue las leyes son obra del consentimiento del pueblo y obligan por igual a gobernados y gobernantes. Los súbditns. en quienes reside el poder politico, tienen el derecho de separar al tirano. Buchanan (1506-1582) sostiene que si cl soberano ha usurpado el gobierno sin el consentimiento del pueblo o si gobierna injustamente. puede ser destronado y aún privado de la vida. Blackstone (1723iz80) sostiene en sus Comentarios de las Leyes de Inglaterra que los súbditos pueden emplear las armas en defensa de sui derechos. cuando hayan agotado los recursos lecales.

Altusio (1557-1638), jurista alemán notable, sostuvo en su "Tratado de la Politica" que la soberanía tiene su origen en el concurso voluntario de los miembros del Fistado y que éstos pueden ejercer una resistencia pasiva contra las leyes injustas, correspondiendo 
a las asambleas públicas la resistencia activa, destituyendo al tirano o condenándolo a muerte. Después de la noche de San Bartolomé, apareció en Francia, entre otros folletos, uno intitulado "Vindiciae contra Tyrannos", atribuído por algunos a Hubert Languet (15181581). Sostiene el autor que los reyes que gobiernan arbitrariamente han quebrantado el compromiso de mantener la justicia y deben ser depuestos.

El art. $7^{\mathbf{0}}$ del Bill de Derechos autoriza a los "súbditos protestantes para tener armas para su defensa". El art. $2^{\circ}$ de las Enmiendas constitucionales de 1789, en los Estados Unidos, reconoce el derecho del pueblo para tener y llevar armas. El art. $2^{\circ}$ de la Declaración de Derechos del Hombre y del Ciudadano reconoce que es un cerecho natural e imprescriptible del hombre la resistencia a la opresión. De este pretendido derecho de resistencia a la opresión se ha hecho toda una doctrina, siendo tradicional reconocerle tres formas: resistencia pasiva o desobeciencia a la ley; resistencia defonsiz'a, por la que el individuo resiste por la fuerza a la ejecución de una ley que él estima contraria a derecho; y resistencia agresira, que consiste en la rebelión con el fin de derrocar al gobierno tiránico. Ningún textó constitucional, ni ninguna Declāración de Derechos ha expresado cuáles son los medios de resistencia a la opresión. Ėn verdad, es cuestión muy delicada, como que equivale a negar la autoridad del Estaço y a entregar el cumplimiento de cada ley al libre albedrío de cada persona.

Desde luego, tratándose de la resistencia pasiva, es admisible el derecho a clesobedecer la ley. Benjamín Constant afirmaba: "La obediencia a la ley es un deber, pero, como todos los deberes, no es absoluto, sino relativo; reposa sobre el supuesto de que la ley tiene in origen legitimc, y se contiene en sus justos limites. Este deber no cesa cuando la ley no se aparta de esta regla, sino bajo ciertos aspectos y hasta cierto punto; debemos al público reposo muchos sacrificios... Pero ningún deber nos liga con leyes que se hacían, por eiemplo, en 1593 y más tarde también, y cuya influencia corruptora amenaza las partes más notables de nuestra existencia". Como opine. Duguit, la ley, sólo por ser ley, no es la rerdad absoluta. "Exigrir I todos la obediencia pasiva a la ley, es querer hacer un pueblo de esclavos. La obediencia a la ley es una necesidad social, pero carla cual es libre de apreciar el valor de ma ley y de hacer todo cuanto pieda, sin recurrir a la violencia, para sustraerse a la aplicación de una ley que él considera contraria al derecho, así como para oponerse a la ejecución de un acto que estima contrario a la ley".

Tratándose de la resistencia defensira el punto es menos claro. En efecto, teóricamente, no puede ser controvertido el derecho de un 
ciudadano de oponerse a la ejecución cle una ley que supone contraria al derecho. Pero, en la práctica, ello equivale a la anarquía. Difícilmente podría subsistir una sociedad en la que se reconociese a cada persona el derecho de oponerse por la fuerza a la ejecución de una ley que estima, por si, ante sí, contraria al derecho. Vendría a quedar sujeta la ley al capricho, al empecinaniento o al interés de cada ciudadano. Además, mirada la cuestión clescle el punto de rista del derecho positivo, es innegable que la resistencia defensiva contra la ley implica un delito de rebelión, puesto que es deber respetar a los funcionarios y agentes del Estado, en uso de sus atribuciones legales. Muy distinto, desde luego, es el caso de un agente del Poder que intente - jecutar un acto abusivo, con violación de la ley, pues entonces se trata simplemente de un acto de fuerza, enteramente ilegal, $y$, por lo tanto, jurídicamente nulo. Nada dice al respecto la legislación penal, pero es evidentemente justa la afirmación que hace Garraud en su "Derecho Penal", de que "no es posible rer un acto de rebelión en la resistencia opuesta a un acto ilegal, incluso cuando sea acompañada de violencias y vías de hecho".

En cuanto a la resistencia agresiz'a, o sea el derecho a la insurrección, es evidente que una revolución que derroca a un gobierno tiránico es un acto legítimo. Claro está que en la práctica. el ejercicio de un derecho semejante presenta graves peligros. Creemos lo más oportuno, en cuestión tan delicada, transcribir la opinión de Duguit: "Si la insurrección triunfase, el gobierno nacido de ella no haría, de seguro, perseguir por atentado a la seguridad del Estado, o por complot revolucionario, a aquéllos a quienes debe el poder; y si fracasara, no habria tribunal que osase declarar que no había habido complot o atentado contra la seguridad del Estado, por ser tiránico el Gobierno y legítima la intención que hubo de clerribarlo". "El derecho a la insurrección, incontestable en teoria, se halla de hecho desproristn de roda eficacia. La ley constitucional de un pais no puede reconocerlo sin peligro cierto de arrojar en el país mismo un gérmen de anarquia. Esto es. precisamente, lo que hacía decir a Boissy d'Anglas que la Constitución de 1793 "había organizado la anarquia". (Informe sobre la Constitución del año III, Monitor). De ahí nace para el Estado una obligación rigurosa: la obligación de organizar los poderes. políticos de manera que quede reducido al mínimum el peligro de que los Gobiernos adopten decisiones arbitrarias, hagan leyes contrarias al derecho, ordenen o permitan la ejecución de actos individuales contrarios a las leyes". 